\title{
A Thermodynamic Study of Adenine and Thymine Substitutions in the Loops of the Oligodeoxyribonucleotide HTel
}

\author{
Yang Li and Robert B. Macgregor, Jr.* \\ June, 2016 \\ Department of Pharmaceutical Sciences \\ University of Toronto
}

*Address correspondence to this author at:

Department of Pharmaceutical Sciences

Leslie Dan Faculty of Pharmacy

University of Toronto

144 College Street

Toronto, Ontario, M5S 3M2 Canada

Phone: 4169787332

Email: rob.macgregor@utoronto.ca 


\section{Supplementary Figures}

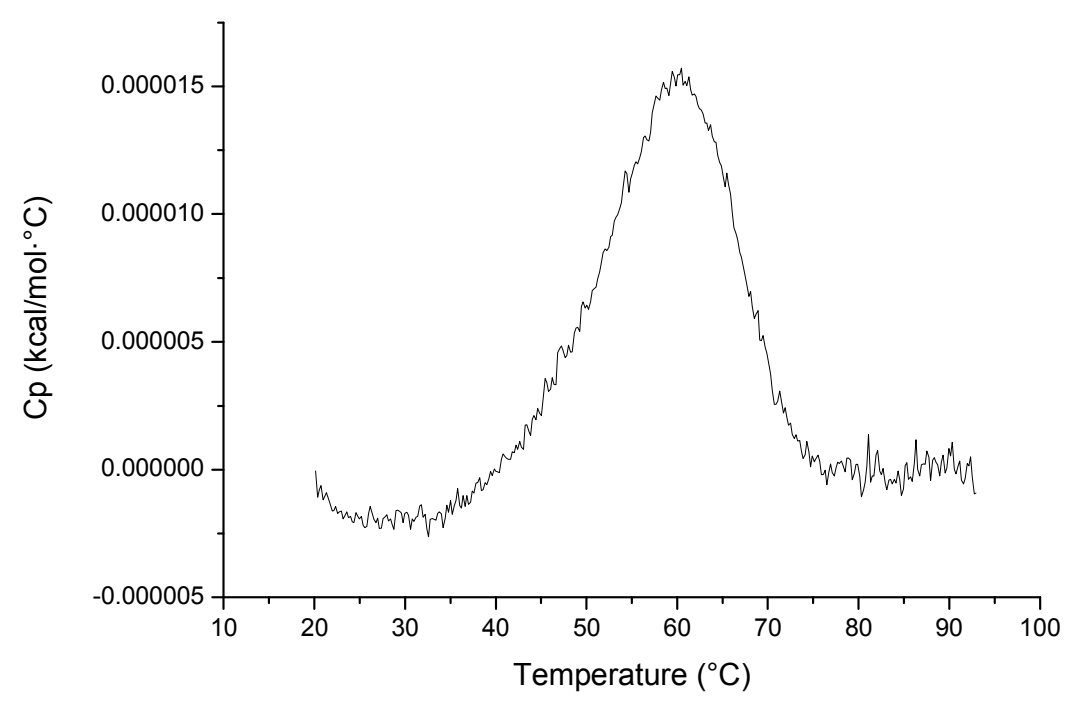

Figure S1: Representative thermal denaturation curve of HTel at $20 \mu \mathrm{M}$ strand concentration in $100 \mathrm{mM} \mathrm{KCl}, 10 \mathrm{mM}$ Tris, and $0.1 \mathrm{mM}$ EDTA, pH 7.5 obtained via differential scanning calorimetry. 


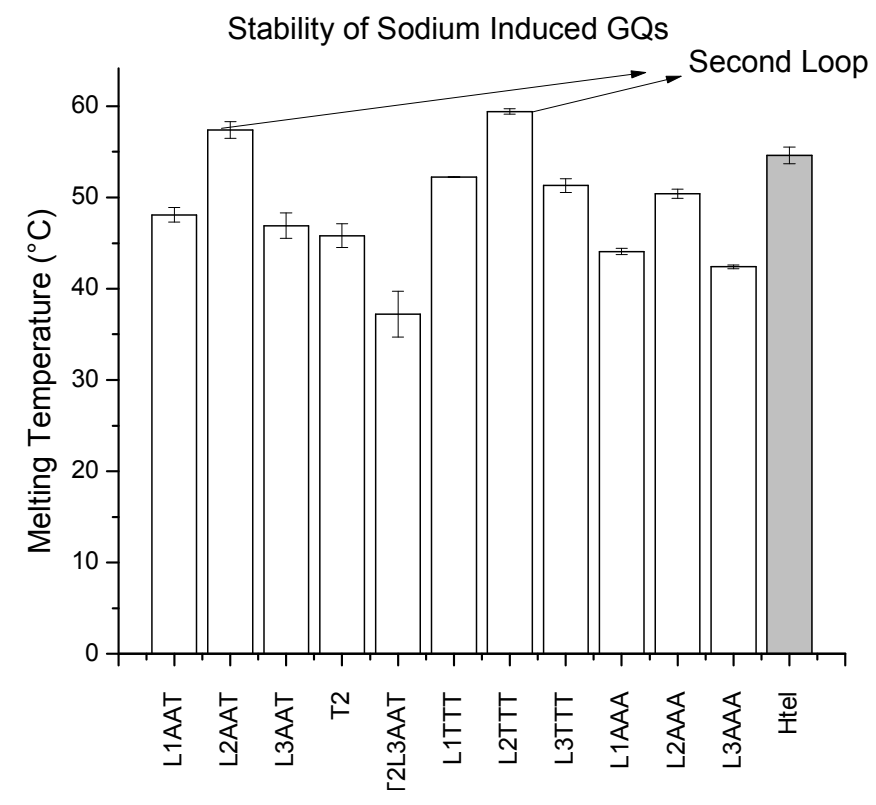

Figure S2 Melting temperatures ( $\mathrm{T}_{\mathrm{m}}$ ) of the ODNs used in this study (Table 1) at $20 \mu \mathrm{M}$ strand concentrations in solutions containing $100 \mathrm{mM} \mathrm{NaCl}, 10 \mathrm{mM}$ Tris, and $0.1 \mathrm{mM}$ EDTA, $\mathrm{pH} 7.5$ obtained via differential scanning calorimetry. 


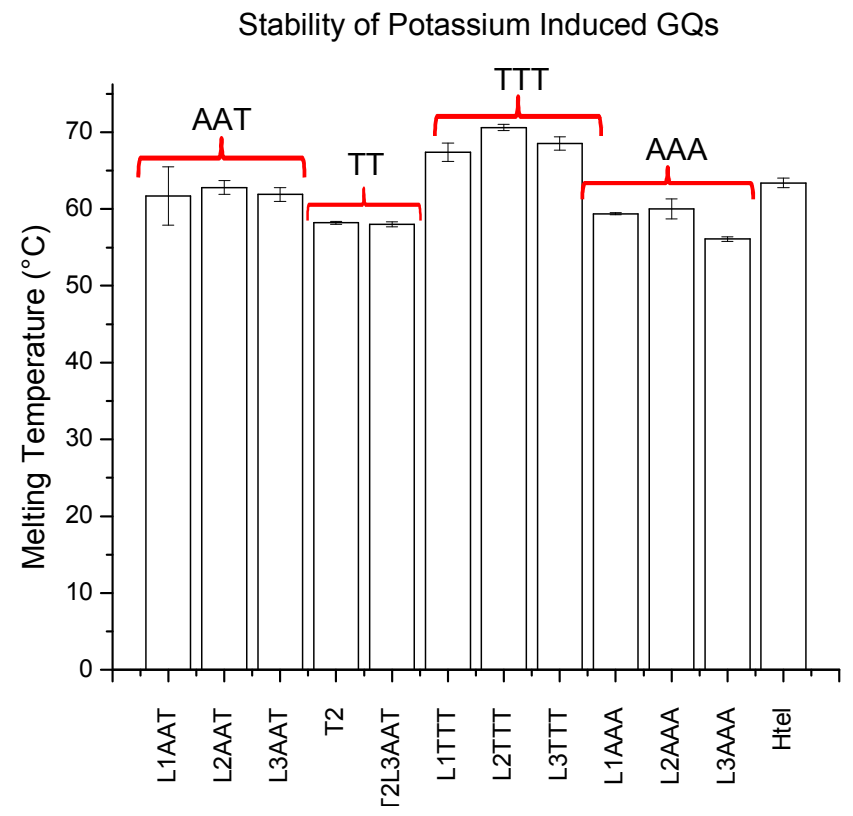

Figure S3 Melting temperatures of the ODNs used in this study (Table 1) at $20 \mu \mathrm{M}$ strand concentrations in solutions containing $100 \mathrm{mM} \mathrm{KCl,} 10 \mathrm{mM}$ Tris, and $0.1 \mathrm{mM}$ EDTA, pH 7.5 obtained via differential scanning calorimetry. 